\title{
Development and Application of Game-Based Learning Software Combining Role-Playing with Problem-Solving Strategies
}

\author{
Shu-Ping Chang \\ Department of Digital Media Design \\ Asia University and Chihlee Institute of Technology, Taiwan \\ Huei-Tse Hou \\ Graduate Institute of Applied Science and Technology \\ National Taiwan University of Science and Technology, Taiwan \\ Rong-Chi Chang \\ Department of Digital Media Design \\ Asia University, Taiwan
}

\begin{abstract}
With the development of educational technology, game-based learning has been gradually applied to teaching practice. This study is divided into two phases. In phase 1, systematic development process was used to develop a simulation e-learning game combining role-playing with problem-solving strategies called "Instructional Design Guidelines - Gem Quest." This game aims to enable learners who intend to act as "gamebased learning instructional designers" in e-learning industry to apply the instructional design knowledge, procedures, and project management skill they have learned, experience the practical work contexts in workplaces, and further use problem-solving strategies to complete tasks in the game before they engage in such work. This game is divided into 5 stages: raw materials, structure, storyboard, product, and online. Learners played the role as the game-based learning designers in the contexts, and had to interact and communicate with the members of various projects in the contexts to implement the projects. The conditions for stage completion and feedback mechanism of the game were designed according to the actual workplace status. Upon completion of this software, Phase 2 is an empirical study was conducted during course instruction to investigate learners' technology acceptance and learning effectiveness of application of this game. The participants were a total of 51 sophomores of Department of Multimedia Design in a certain university in the northern Taiwan. The research results showed that, learners' technology acceptance of this game is above the median, and there is a significant difference in their stage completion and posttest scores.
\end{abstract}

\section{INTRODUCTION}

Digital games have been gradually applied to teaching practice and provided teachers with more diversified teaching methods. In recent years, many empirical studies have further verified that digital games have a positive effect on teaching (Kirriemuir \& McFarlane, 2004; Pivec, Dziabenko \& Schinnerl, 2003; Prensky, 2007, 2003; Squire, 2005). Some studies also have found that game-based learning environment can provide learners with the chance to cultivate conceptual knowledge and engage in practices. In game-based learning environment, learners are more willing to actively participate in activities out of intrinsic motivation, and game-based learning environment can effectively improve learners' concentration (Raybourn \& Bos, 2005). 
Prensky (2007) generalized several characteristics of digital games to explain the reason they can trigger learners' learning motivation: the form of fun provides learners with fun and pleasure; the form of play provides learners with passionate fun; targeted digital games provides learners with motivation; result and feedback enable learners to learn knowledge; victory in games provides learners with ego gratification. Many researchers (McFarlane, Sparrowhawk, \& Heald, 2002; Prensky, 2007; Robertson \& Howells, 2008) suggested that an interesting and challenging teaching strategy is the so-called game-based learning (GBL). GBL not only provides knowledge of subject content, but also assistive learning tools to enable students to participate in problem-solving or overcome challenges. GBL uses digital games to trigger students' active participation to improve their learning motivation and effectiveness, as well as to successfully enable them to obtain a sense of accomplishment (Prensky, 2007).

Role-playing originated from a psychodrama. After the psychologist, Moreno, made amendments and performed many studies on role-playing, role-playing teaching method became an important teaching technique. Moreno (1920) suggested that role-playing is to provide individuals with the chance to learn role-playing and play a role or engage in a behavior that does not belong to them in real life and, as well as to try or experience another lifestyle and behavioral model to increase role learning and expand living knowledge. Learners can learn more role models by continue practicing, which increases their flexibility to respond to living environment.

Problem-solving learning is to place learners in a meaningful learning context where the learning focus is on solving the problems in an authentic context. Under the situation where necessary resources and adequate guidance for problem-solving are provided, learners are able to actively establish knowledge and develop problem-solving skills during problemsolving process (Mayo, Donnelly, Nash, \& Schwartz, 1993). Dempsey, Lucassen, Haynes, \& Casey (1996) found that adventure games and simulation games can help adults develop problem-solving skills and decision-making ability.

Application of information technology to teaching and learning has become a global trend, and various countries around the world have included the promotion of e-learning as important national policies one by one. In order to increase the need for talents in e-learning industry, higher education in Taiwan has endeavored to cultivate "e-learning instructional designer(eID)" engage in the analysis, design, development, implementation, and assessment of e-learning projects, to make sure that the developmental details of e-learning courses and the development of courseware meet the design specifications and customers' need (Yang, Lin, Chang, \& Tseng, 2008). However, according to relevant studies, because university students do not have sufficient work experiences in society, there is still a gap between the e-learningrelated knowledge and skills they learn during school period and those in workplace (He, $\mathrm{Li}, \&$ Liao, 2009).

Therefore, this study designed a game-based learning software using work context of eLearning Instructional Design as background, and provided it for application in the preemployment training of eID. The game levels were designed according to role-playing and theoretical basis of problem-solving to provide learners with the chance to clarify and understand problems, collect data, analyze data, and implement problem-solving in e-learning projects. Upon the development of the software, the software was actually applied to the empirical study on the course of "design of game-based learning and teaching" for sophomores as instructed by the researcher. It was hoped that the integration of game-based learning could 
enable learners to use thinking to associate with knowledge or experiences to further improve problem-solving ability.

\section{DEVELOPMENT OF SOFTWARE}

The development of software is divided into 2 phases:

Phase 1 Qualitative Analysis: Game-based Learning as Focus

Based on literature review, this study investigated the functions of eID. This study invited three focus companies who hire eID to receive interviews, and used qualitative analysis to summarize common problems faced by e-learning designers in workplace. In phase 1 , this study converted the interview content to transcripts, and performed qualitative content analysis on the transcripts. This study used the work content of eID and divided it into 5 major categories: raw material, structure, storyboard, product, and online.

Phase 2 Development of Game-based Learning Software

\section{Design Concept}

This study used FLASH CS6 to develop the game-based software that can be run on various browsers. This software will be subsequently applied to departments concerning the cultivation of e-learning talents in Taiwan or used in courses or units concerning e-learning design in educational training institutes.

For the game mechanism and corresponding theoretical bases. This study used situational learning (Brown et al., 1989) to make the design style of the game close to actual work content. Moreover, this study also referred to role-playing teaching method and problem-solving process (Dewey, 1910) to design the game. In the game, learners played the leading role of the story - "eID," and controlled and operated all of the objects in the game content. Moreover, they further found out the objects hidden in the scenes and complete their tasks.

For multimedia performances of the game, this study referred to the scaffolding theory proposed by Wood, Brune, \& Ross (1976) to provide instant feedback and reminder message. There were explanations provided for all of the accessible objects. To make the game more complete, challenging, and interesting (Prensky, 2007), this study set up a time limit on the plot design, which also conformed to the actual project schedule $\mathrm{n}$ real workplace. Learners had to complete the main content of 5 stages of e-learning design within the time limit. In order to enhance learners' feeling of indulgence in the game, background music was added to the game to enable learners to integrate themselves with the atmosphere. In addition, the uncertainty and urgency of the task itself also made them concentrate more on the game.

\section{Characteristics of Software and Operational}

This study integrated the card game popular with university students with the training course of novice eID, and designed the common problems faced in workplace as 10 challenges/tasks to enable learners to play the role of challenger and naturally learn the course focuses, as shown in Figure 1. 

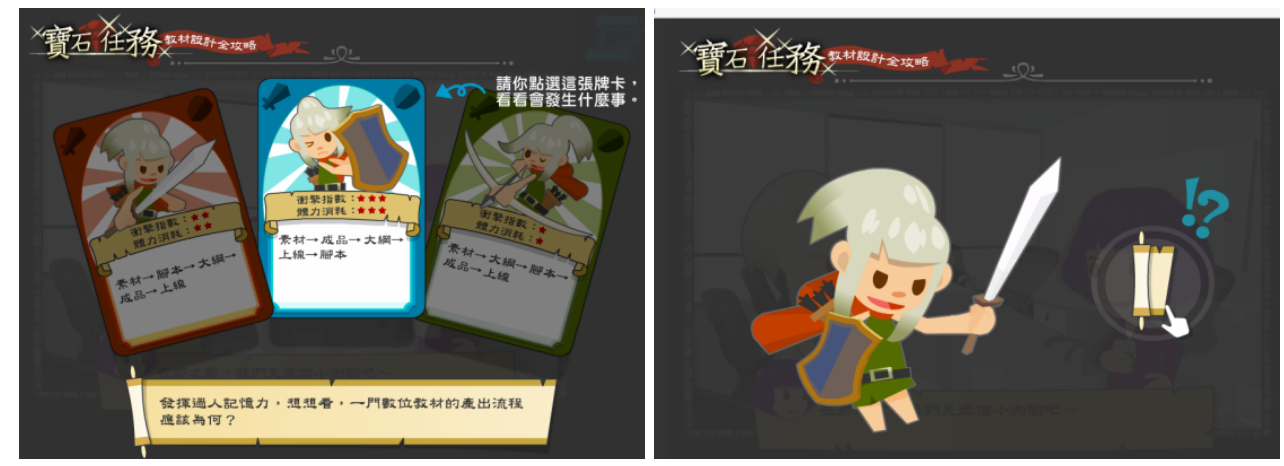

Figure 1 Diagram of Card Game Screen

When students challenged the game levels, their game-based learning progress would be displayed in the bottom of the screen. The right side of the screen displays: Level index, heart of life index, and gem reservoir to enable learners to fully grasp their own learning progress and status, as shown in Figure 2.
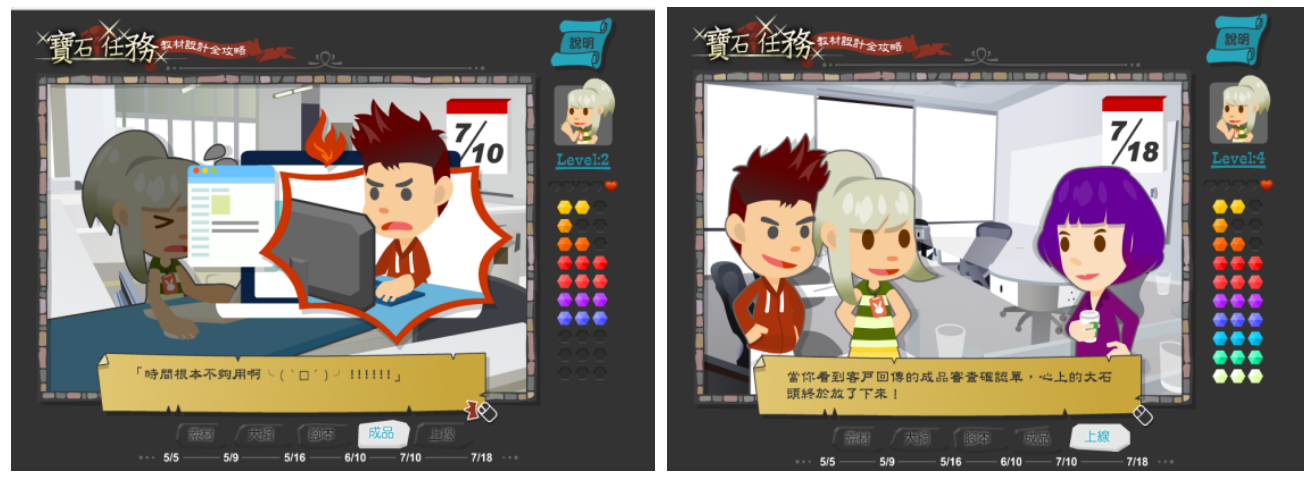

Figure 2 Diagram of Game-based Learning Progress

In the beginning of the game, learners were requested to sign their names on the declaration of war to increase their level of participation. Their scores of completion of challenges/tasks would be displayed by the end of the game, and learners could print it to share with other people, which also attracted people interested in the game to participate in it, as shown in Figure 3.
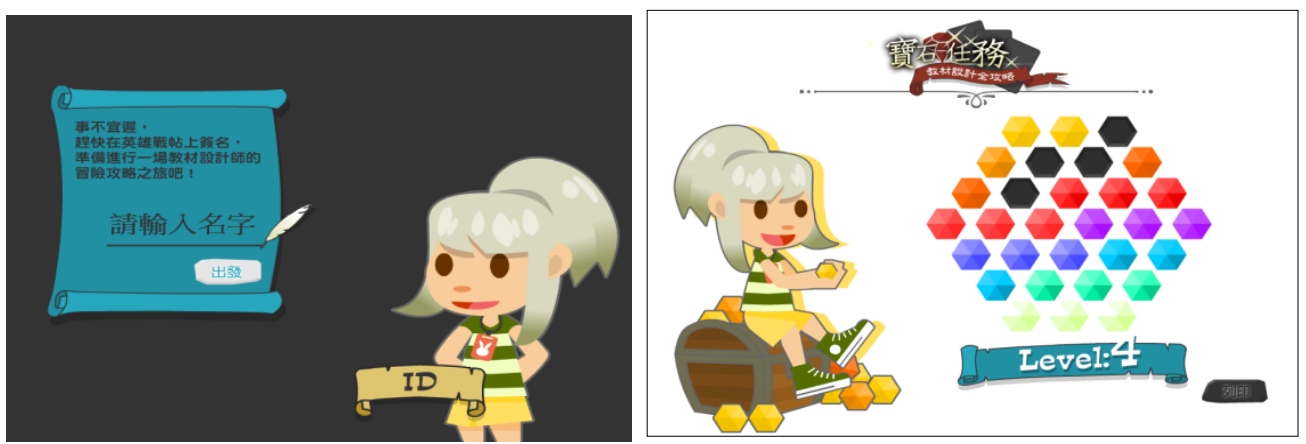

Figure 3 Diagram of Individualized Learning Record

\section{RESEARCH METHOD}

In order to understand the learning effectiveness of university students after playing the gamebased learning game designed by this study, this study designed pre-and-post tests. Upon compilation of the items of tests, this study enrolled 38 sophomores of Department of Multimedia Design of night school of a certain university in the northern Taiwan to participate in the pre-test, in order to understand the reliability of the research tool. Cronbach $\alpha$ 
coefficient of the total scale reached .892, suggesting that the internal consistency of the subscales of various dimensions and total score is high. Therefore, the reliability is high enough to support the research results.

The research subjects of this study were a total of 51 sophomores (15 male sophomores and 36 female sophomores) of Department of Multimedia Design of day school of a certain university in the northern Taiwan. All of the subjects had attended the course of e-learning design and had never played the game. Their average age was 19.

In order to understand learners' technology acceptance of the game, in addition to the pre-test, this study also referred to the scale on technology acceptance assessment developed by Davis (1989) and designed 6 items (the dimensions are perceived usefulness and perceived ease of use). After analysis on the scale completed by the subjects, the overall reliability was 0.67 (Cronbach's $\alpha=0.67$ ).

Table 3 Scale on Technology Acceptance Assessment

\begin{tabular}{|c|c|c|c|}
\hline Item No. & Item & Dimension & Reference \\
\hline Q1 & $\begin{array}{l}\text { Do you feel that the teaching material design Instructional Design Guidelines- Gem } \\
\text { Quest can help you better understand the notices in e-learning design work in } \\
\text { workplace? }\end{array}$ & \multirow{3}{*}{$\begin{array}{l}\text { Perceived } \\
\text { usefulness }\end{array}$} & \multirow{6}{*}{ Davis (1989) } \\
\hline Q2 & $\begin{array}{l}\text { Do you feel that the teaching material design Instructional Design Guidelines- Gem } \\
\text { Quest can help you better understand the priority of e-learning design work? }\end{array}$ & & \\
\hline Q3 & $\begin{array}{l}\text { Do you feel that, compared to textbook, the teaching material design Instructional } \\
\text { Design Guidelines- Gem Quest can help you better understand the notices in e- } \\
\text { learning design work and teamwork? }\end{array}$ & & \\
\hline Q4 & $\begin{array}{l}\text { Do you feel that it is easy to operate the teaching material design Instructional } \\
\text { Design Guidelines- Gem Quest? }\end{array}$ & \multirow{3}{*}{$\begin{array}{l}\text { Perceived } \\
\text { ease of use }\end{array}$} & \\
\hline Q5 & $\begin{array}{l}\text { Do you feel that it is easy to understand the logic of the plot of the teaching material } \\
\text { design Instructional Design Guidelines- Gem Quest? }\end{array}$ & & \\
\hline Q6 & $\begin{array}{l}\text { Do you feel that the teaching material design Instructional Design Guidelines- Gem } \\
\text { Quest can be operated smoothly without making any mistake? }\end{array}$ & & \\
\hline
\end{tabular}

Source: Compiled by this study

This study conducted the experiment in computer class, and the class lasted for a total of 50 minutes. Before the experiment was initiated, the students were requested to complete the pre-test. The researcher explained to them the operation of game system for approximately 10 minutes first, and then explained and demonstrated how to use and operate props on the interface of the game. However, any content concerning the game themes and learning themes was not disclosed. Afterwards, the experiment of the game was conducted for 30 minutes. During the experiment, the subjects had to wear headphones, and were not allowed to talk to anyone. By the end of the game, the subjects had to complete the post-test and scale on technology acceptance assessment whether they succeed or fail in the challenges/games.

\section{CONCLUSION AND SUGGESTION}

The difference between pre-test score and post-test score of the subjects reached significance $(\mathrm{t}=-9.571, \mathrm{p}<.05)$, suggesting that the students' performance in post-test was superior to that in the pre-test. Therefore, the use of this software helped improve students' learning.

The two dimensions of technology acceptance were distributed in 6 items of the scale on technology acceptance assessment. The first three items belonged to the dimension of perceived usefulness, while the last three items belonged to that of perceived ease of use. $90.1 \%$ of the learners agreed with or strongly agreed with "The game can help you better understand the notices in e-learning design work." $86.2 \%$ of them agreed with or strongly 
agreed with "The game can help you better understand the priority of e-learning design work." $84.3 \%$ of them agreed with or strongly agreed with "Compared to textbook, the game can help you better understand the notices in teamwork." $82.3 \%$ of them agreed with or strongly agreed with "It is easy to operate the game." $84.3 \%$ of them agreed with or strongly agreed with "It is easy to understand the logic of plot of the game." $78.4 \%$ of them agreed with or strongly agreed with "The game can be operated smoothly without making any mistake." The results above showed that, at least $80 \%$ of the students agreed with or strongly agreed with "The game can help you better understand the notices in e-learning design work," "The game can help you better understand the priority of e-learning design work," "Compared to textbook, the game can help you better understand the notices in teamwork," "It is easy to understand the logic of plot of the game."

The purpose of this study is to design game-based learning software integrated teaching strategies of role-playing content with teaching with problem-solving for pre-employment training of eID. The suggestions on future studies are as follows:

(1) Software trial: It is advised to invite users to participate in large-scale software trial, in order to revise or adjust various aspects and design bases of the game, such as interface, figure, and level completion mechanism. Moreover, such information can also be provided as reference for development of other project-based roles in games.

(2) Assessment on learning effectiveness: After this study's development of the game-based learning software integrating role-playing with problem-solving strategies, empirical research methods can be further used to understand learners' flow assessment after the use of this software, as well as to analyze and investigate the connection of error types.

(3) Analysis on behavioral model: During the game, many operational behaviors of learner were recorded. If learners' operational process can be understood and further analyzed and investigated based on their behavioral records, learners can understand their selflearning status and be provided with suggestions on learning. Therefore, future studies are advised to use other analysis methods, such as sequential analysis of behaviors (e.g., Hou, 2012), to investigate learners' behavioral process in the game, as well as to investigate their learning behaviors and improvement methods.

\section{References}

Alberto, P., \& Troutman, A. C. (1999). Applied behavior analysis for teachers (5th ed.). Upper Saddle River, N.J.: Merrill.

Brown, J. S., Collins, A., \& Duguid, P. (1989). Situated Cognition and the culture of learning. Educational Researcher, 18(1), 32-42.

Davis, F. D. (1989). Perceived usefulness, perceived ease of use, and user acceptance of information technology. MIS Quartely, 13(3), 319-39.

Dempsey, J. V., Lucassen, B., Haynes, L., \& Casey, M. (1996). Instructional Applications of computer games. ERIC Document Reproduction Service No. ED394500.

Dewey, J. (1910). How we think. Mineola, New York: Dover.

Ho, L.A., Lee, X. S.\& Liao, F.J.(2009). The Competences of e-learning instructional designers. Bulletin of National Pingtung Unversity of Eduction, v32, p295-332.

Hou, H. T. (2012). Exploring the behavioral patterns of learners in an educational massively multiple online roleplaying game (MMORPG), Computers \& Education, 58, 1225-1233.

Kirriemuir, J. \& McFarlane, A. (2004). Literature review in games and learning. Bristol: Nestafuturelab.

Mayo, P., Donnelly, M. B., Nash, P. P., \& Schwartz, R. W. (1993). Student Perceptions of Tutor Effectiveness in problem based surgery clerkship.Teaching and Learning in Medicine, 5(4), 227-233.

McFarlane, A., Sparrowhawk, A., \& Heald, Y. (2002). Report on the educational use of computer games. Cambridge. 
Pivec, M., Dziabenko, O., \& Schinnerl, I. (2003). Aspects of Game-Based Learning. the Third International Conference on Knowledge Management.

Prensky, M. (2003). Digital Game-Based Learning. Computers in Entertainment, 1(1), 21-21.

Prensky, M. (2007). Digital Game-Based Learning. New York: McGraw-Hill.

Prensky, M., \& Thiagarajan, S. (2007). Digital game-based learning. St. Paul, MN: Paragon House.

Raybourn, E. M., \& Bos, N. (2005). Design and evaluation challenges of serious games. Proceeding of the SIGCHI conference on Human factors in computing systems, 2049-2050.

Robertson, J., \& Howells, C. (2008). Computer game design: Opportunities for successful learning. Computers \& Education, 50(2), 559-578.

Shaftel, F. R., \& Shaftel, G. (1967). Role-playing for social values: decision-making in the social studies. PrenticeHall.

Squire, K. D. (2005). Game-based learning: Present and future state of the field. Saratoga Springs, NY: MASIE Center e-Learning Consortium.

Wood, D., Bruner, J., \& Ross, G. (1976). The role of tutoring in problem solving. Journal of Child Psychology and Psychiatry, 17, 89-100. 